\title{
Bibliometric Study of the Bachelor Theses on Oral Pathology Defended at the University of the Andes School of Dentistry, 2009-2019
}

\author{
Geraldine Sulbarán ${ }^{1}$ and Damian Cloquell ${ }^{2, *}$ \\ ${ }^{1}$ Student of the Faculty of Dentistry, University of the Andes, Mérida, Venezuela \\ ${ }^{2}$ Professor of the Research Department, Faculty of Dentistry, University of the Andes, Mérida, Venezuela
}

*Corresponding author: Damian Cloquell, Professor of the Research Department, Faculty of Dentistry, University of the Andes, Mérida, Venezuela, E-mail: cloquellale@gmail.com

Received: 28 Jan, 2021 | Accepted: 02 Mar, 2021 | Published: 19 Mar, 2021

Citation: Sulbarán G, Cloquell D (2021) Bibliometric Study of the Bachelor Theses on Oral Pathology Defended at the University of the Andes School of Dentistry, 2009-2019. Int J Dent Oral Health 7(3): dx.doi.org/10.16966/2378-7090.353

Copyright: (2021 Sulbarán G, et al. This is an open-access article distributed under the terms of the Creative Commons Attribution License, which permits unrestricted use, distribution, and reproduction in any medium, provided the original author and source are credited.

\begin{abstract}
Oral or Buccal Pathology is a dental specialty based on Pathological Anatomy and Internal Medicine that studies the etiology, pathophysiological mechanisms and consequences of diseases that develop and manifest in the oral and maxillofacial region, being the basis for treatment and management of them. For this reason, it represents an area of importance in the university career, especially at the time of the presentation of the Undergraduate Degree Projects, which can be analyzed through bibliometrics. The study aimed to identify the behavior of the bibliometric indicators used for the undergraduate theses in the Stomatology area at the Faculty of Dentistry, University of The Andes (FOULA due to the acronym in Spanish) between the years 2009-2019. The research was descriptive with a documentary design. The analytical material was constituted by the FOULA Stomatology theses in digital format, from the Technical Council, and the database of the FOULA Research Department during the period 2009-2019. A total of 53 theses were conducted in the Stomatology area during that period, 4.81 papers per year, Vancouver citations were presented in $75.47 \%$ of the thesis; with an average of $52.98 \%$ references per thesis, it predominated the descriptive research type with $58.49 \%$ and transversal design with $60.78 \%$; the prominent collection technique was observation with $18.86 \%$ and analysis of descriptive data with $64.15 \%$.
\end{abstract}

Keywords: Bibliometry; Bibliometric indicators; Undergraduate theses; Oral pathology; Stomatology

\section{Introduction}

Oral or Buccal Pathology is a branch of dentistry that study the nature, identification and treatment of the alterations and diseases located in the oral cavity, maxilla, mandible and teeth, (including all the structures that make it up), as well as the link that these have with systematic problems. It is a science that studies the causes, processes and effects of the diseases that affect the oral and maxillofacial complex. The practice of Oral Pathology includes investigation and diagnosis using clinical, radiographic, microscopical and biochemical examinations as well as the management of the pathological entity [1]. This dental area is important within the educational system implemented by the Faculty of Dentistry of the University of The Andes (FOULA) and is taught in the course called Stomatology, which even encourages the research and publication in that area in which the student is involved from the third year to the culmination of the career, among these publications are the Undergraduate Degree Projects (UDP).

The UDP or thesis is an original and unpublished written paper that reports the results of an investigation on topics related to science in the area of knowledge that it deals with [2-6], being the last requirement to opt for an academic degree and requires the approval of an evaluating jury [6,7]. The type and timeliness of the literature, and the different sources of information used for its development, are elements that can be analyzed and studied through bibliometrics $[5,6,8]$.

Bibliometry is the science that allows the quantitative analysis of scientific production through literature, studying the nature and course of a scientific discipline, using different quantitative and qualitative indicators [2,5-13]. At the same time, the use of bibliometric indicators provides information on the results of the research process, its volume, evolution, visibility and structure which can be carried out by a country, institution, research group or individual, determining the growth of any field of science, which allows the assessment of scientific activity and influence both from paper and from sources [2,5-10]. For this, they can be classified into 5 groups of indicators: personal indicators, productivity indicators, citation indicators, content indicators and methodological indicators. These are applied mainly in journals, in doctoral theses and UDPs for their study $[2,6,8,9,11]$.

It is worth mentioning that bibliometric studies have made it possible to evaluate and describe the scientific production generated 
in dental journals [9-12,14-19] and to a lesser extent in UDP. Regarding the UDPs, Maggiorani J, et al., carried out a study whose objective was to identify the behavior of the bibliometric indicators of the undergraduate theses of the Faculty of Dentistry of the University of The Andes (FOULA), between the years 2005-2017, in this study, the indicators were described by calendar year production, as well the thematic content indicator and the methodological indicator [6]. 515 UDPs were analyzed, where Stomatology was the third studied area with a total of $43(8.34 \%)$.

Likewise, in Peru, several studies have been found, for example, Ordinola-Sierra C, et al., indicate that during the period 2005-2013 the total production of undergraduate theses in the Faculty of Dentistry of the University of San Martín de Porres was 464, where the second most addressed specialty was Oral Medicine and Pathology with 54 papers (11.63\%) [20]. However, Castro YR, et al., in 2018 evaluated 269 UDP supported and registered in the library system of the National University of San Marcos from 2005 to 2015, in which, the subject with the lowest study rate was related to Oral Medicine with $1(0.4 \%)$ [21]. Similarly, another study carried out in the same country appears as the third area that is less frequently investigated [3].

Meanwhile, at the Antenor Orrego Private University [22], the results indicate that in the last six years 368 theses were presented in the institution, $4.35 \%$ (16) of these correspond to Oral Medicine.

Although there is research that not only refers to the frequency in which the Oral Pathology area is studied in journals or theses until now no scientific evidence has been found about the evaluation in the behavior of these indicators on undergraduate UDPs of the FOULA in the Stomatology area. For this reason, the purpose of this research is to identify the behavior of bibliometric indicators of production by calendar year, thematic content and the methodological indicators used in the undergraduate theses of FOULA in the Stomatology field in the last eleven years (2009-2019).

\section{Materials and Methods}

It consists of a descriptive level study with a documentary design, where bibliometric indicators were used based on the collection and analysis of the information contained in the FOULA Stomatology UDPs from 2009 to 2019. For data collection, a registration matrix was used as an instrument, created and validated by Maggiorani J, et al., [6] which consists of seventeen columns: inherent to the year of production, the title of the UDP, tutor's name, tutor's chair, legal bases, number of background, type of research, approach, research design, pathology studied, sub-area of study, study units, data collection technique, bioethical aspects, use of statistics (it is subdivided into fourteen columns for each of the types of statistics used), critical apparatus and number of references respectively, it also presents 53 rows for the registration of each of the thesis in the Stomatology area. The methodological sequence was carried out independently by three researchers.

1. Identification of the UDP of Stomatology and other areas whose content included oral pathology, oral lesions or systemic diseases with oral repercussions. For this purpose, the title was read. If the title did not clarify whether or not the thesis was a stomatology thesis, the abstract was read.

2. Location and count of related UDPs from 2009 to 2019.

3. A detailed reading of each of the related UDPs and their subsequent emptying, systematization and coding in the content matrix.
4. Analysis of the data obtained to respond to the study objectives.

\section{Exclusion criteria}

Although stomatology covers the entire Oral Pathology area, those studies that were considered more specific to other areas were excluded:

- Diagnosis or treatment of pathologies that affect the oral cavity in patients under 12 years of age (Pediatric Dentistry Area).

- Those that used pharmacological products in rats (Pharmacology area).

- Those that were histopathological analyzes where the presence of pathology was not clinically diagnosed (Pathological Anatomy area).

- Those that addressed treatments of periodontal pathologies or caries (areas of Periodontology and Operative Dentistry respectively).

\section{Analysis plan}

The data were tabulated in a database (MS Excel ${ }^{\oplus}$, Microsoft Corp., USA), to describe the production indicator by calendar year, tables and graphs were also elaborated, this point the total and relative production (percentage) combined with the methodological indicator represented by scientific paradigm, number of antecedents, legal bases, bioethical aspects, the object of study, critical apparatus, approach, type, design, data collection technique and analysis technique of data. Also, the chairs in which the tutors of the UDPs were ascribed were described.

\section{Results}

\section{Production indicator by calendar year}

The results of this research were based on the 53 UDPs in the FOULA Stomatology area out of the total of 447 existing between 2009 and 2019. An average of 4.81 papers was presented per year, the most prolific year being 2012 with a frequency of 18.92 of the totals made that year. It is remarkable the decrease in the UDPs related to Stomatology in the last two years (2018 and 2019), representing just $6.94 \%$ of the total UDPs.

In turn, a total of 15 different chairs carried out UDP of Stomatology. It was determined that the UDPs tutors who stood out the most were those of the Stomatology chair with $22.64 \%$, followed by the professors of the Pathological Anatomy chair with 16.98\% (Images 1 and 2).

\section{Thematic content index}

Its dimensions correspond to theory (legal bases, bioethical aspects, antecedents, references and critical apparatus), design (focus, type and research design) and techniques (data collection and data analysis).

The Legal Bases, located in the theoretical framework, did not represent any result, while the Bioethical Aspects depicted in the methodological framework, were presented in $58 \%$ of the 53 Stomatology UDPs, its presence was observed as of 2010 and presented in $100 \%$ of the 10 papers between 2017 and 2019.

The background presented an average of 13.19 by UDP on Stomatology, while the average of references was 52.98 by UDP. Beyond the fact that the lowest average of antecedents was presented in 2013, it stands out that in the last 4 years (between 2016 and 2019) the average was 10.56. The average of referrals, meanwhile, has been very irregular over the years after the decline between 2011 and 2013 (Image 3). 
About the critical apparatus, 40 studies used Vancouver (75.47\%). However, since 2013, citations under the Vancouver standards criteria were presented in $90.32 \%$ of the cases, and even in the periods 2013 , $2014,2016,2018,2019$ it was developed in its entirety with this citation system (Images 4 and 5).

$52.83 \%$ of the studies analyzed did not specify the type of approach used. However, among those who did identify it, $84 \%$ represent the quantitative approach and $16 \%$ the qualitative one (Image 6).
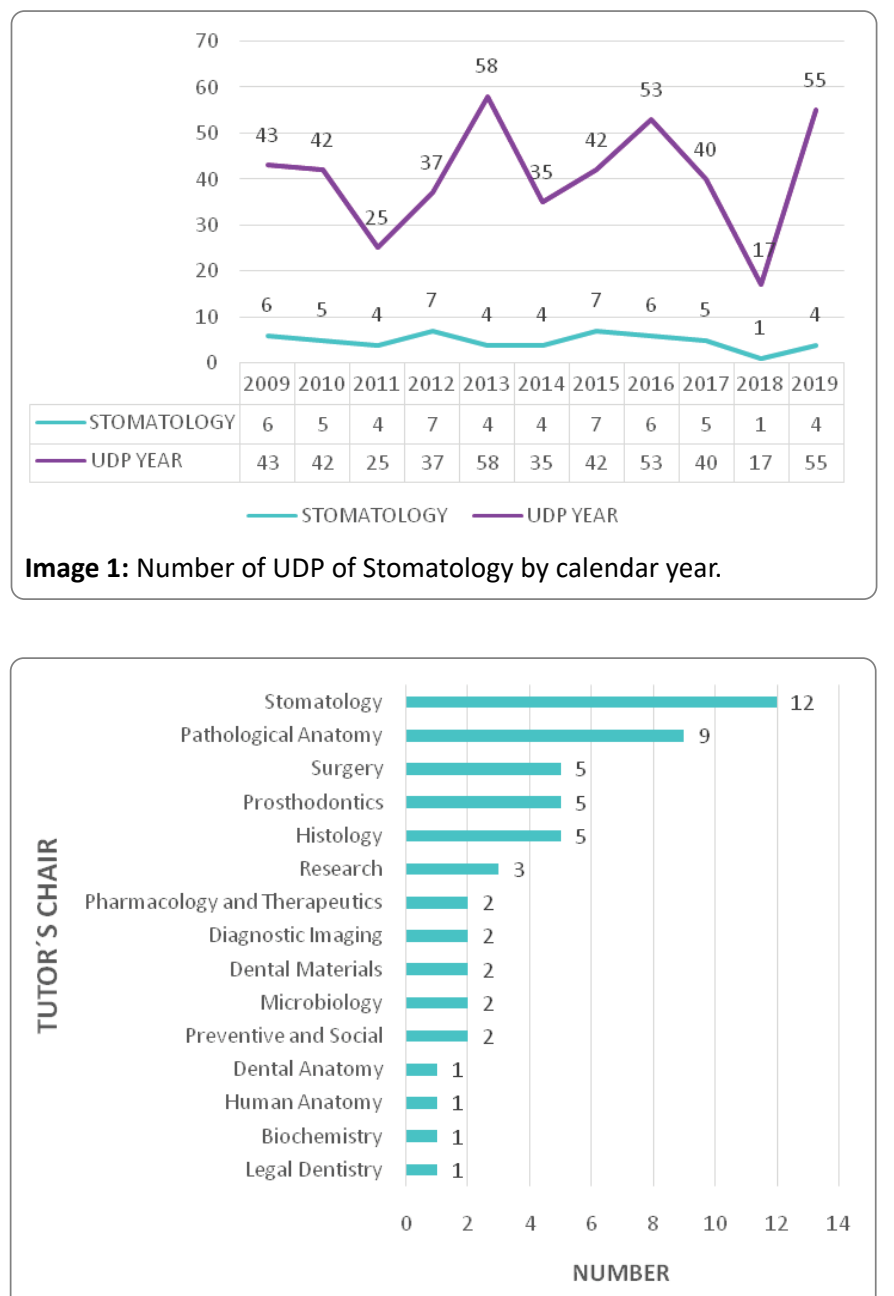

Image 2: Number of UDP of Stomatology by tutor's chair.

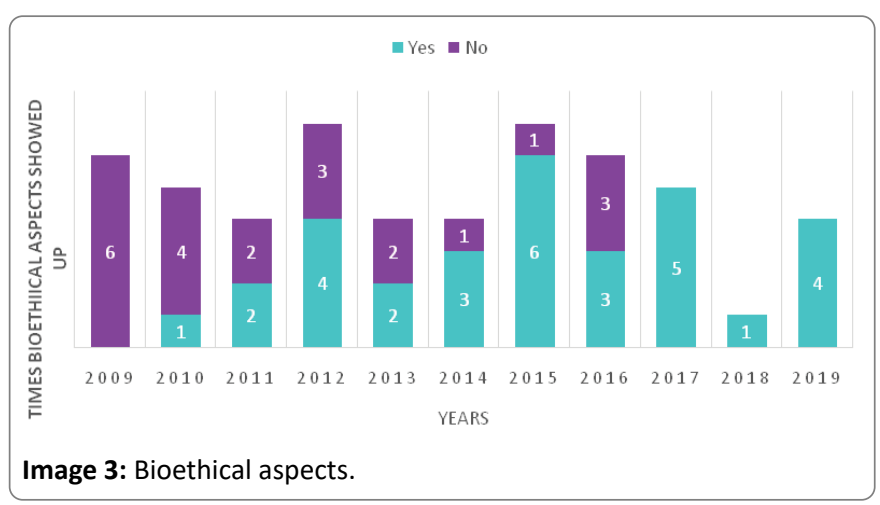

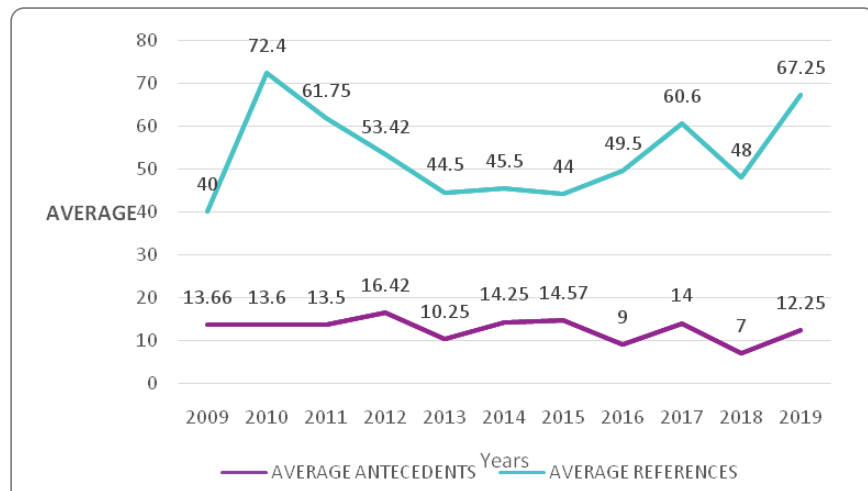

Image 4: Number and average of antecedents and references per year of the Stomatology UDPs.

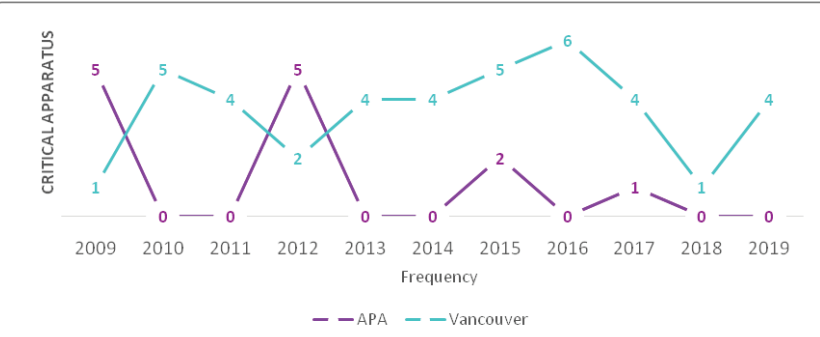

Image 5: Critical apparatus.

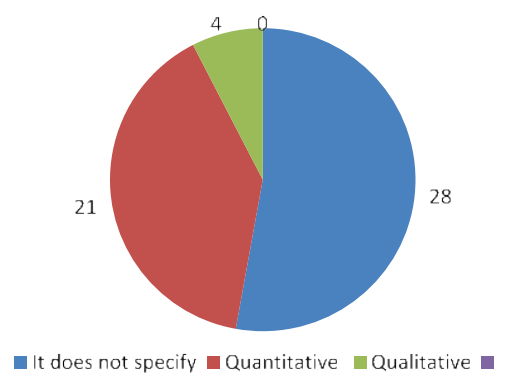

Image 6: Research approaches used in the Stomatology UDPs.

When examining the number of errors in the approaches, it is observed that $55.56 \%$ do not indicate the methodological author, and $22.22 \%$ pointed to an author who is not methodological, reflecting a total error rate of $36 \%$ (9 of the 25 cases) (Image 7).

According to the type of research, the descriptive type was found in $58.49 \%$ of the total of Stomatology UDPs reviewed, followed by the explanatory one with $5.66 \%$. However, there was a considerable number of UDPs that mixed the type of research with some design (11.32\%), others UDP used the type of comparative research (7.54\%) being unappropriated according to the methodological author, and the same happened with the 3 descriptive types. Likewise, the total number of possible errors when describing the type of research was $32.07 \%$ (17 of 53), counting among them those who merged two types of research, placed a design or missed the type (Image 8).

In this sense, taking into account those studies that expressed the type of research (52 out of 53), it was found that $30.77 \%$ cited Hernández R, et al., followed by $17.31 \%$ who used Hurtado J, while the $15.38 \%$ of the studies did not specify the author $[23,24]$. Hurtado 


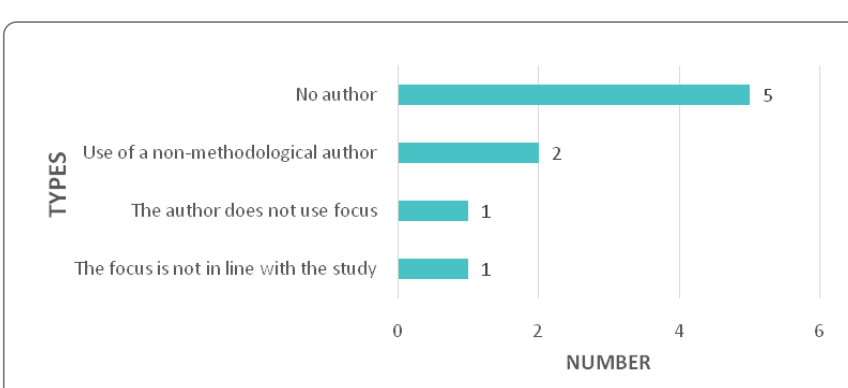

Image 7: Errors in the research approach on Stomatology UDPs.

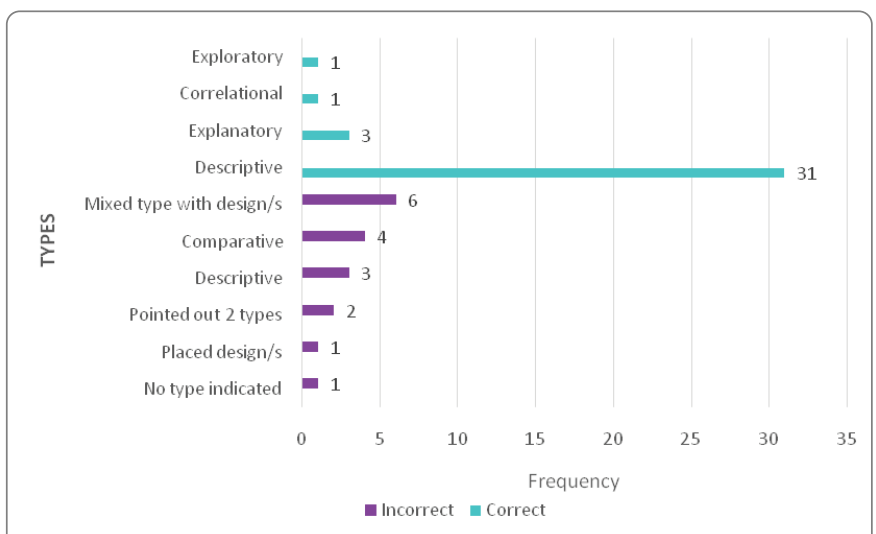

Image 8: Research types and errors within the types.

J, et al., was also misused concerning his criteria in $7.69 \%$ of the cases and Hernández R, et al., in $3.85 \%$. The sum of possible flaws when describing the methodological authors in the type of research reached a total of $42.31 \%$ (Image 9) $[23,24]$.

Regarding the study's design, these were indicated in 51 of the 53 Stomatology UDPs, as can be seen in table 1 more than half of the UDPs, $60.78 \%$ had a cross-sectional design (being part of the design by several measurements which represents $81.58 \%$ ). According to the Intervention, $27.45 \%$ were observational or non-experimental (58.33\% for this type of design); in terms of the period in which the information is captured, $17.65 \%$ were retrospective $(64.29 \%$ for this type of design). According to the source, the field design stood out with $15.69 \%$ ( $57.14 \%$ for this type of design).

In the same way, methodological authors who indicate the design of the research, $13.21 \%$ indicated to have cited in their UDPs Hernández $\mathrm{R}$, et al., the same percentage when using Hurtado J and Hernández $\mathrm{R}$, et al., in an incomplete way according to the taxonomy that these authors handle. In $67.92 \%$ there was a possible methodological error when indicating the author used 14 types of failures (Table 2) $[23,24]$.

When analyzing the distribution by topic to be treated in the UDPs, 34 different research lines were studied, predominating those concerning subprosthetic stomatitis with $9.49 \%$ in second place those of oral-dental alterations, oral candidiasis, lesions and oral-dental pathologies, as well as lip pathologies with a frequency of $5.66 \%$ each (Image 10).

Next, the data collection technique was analyzed, where the most used was an observation, which represents $18.86 \%$, followed by the survey, clinical examination and documentary analysis; however, it is important to note that $35.85 \%$ mistake when indicating the technique

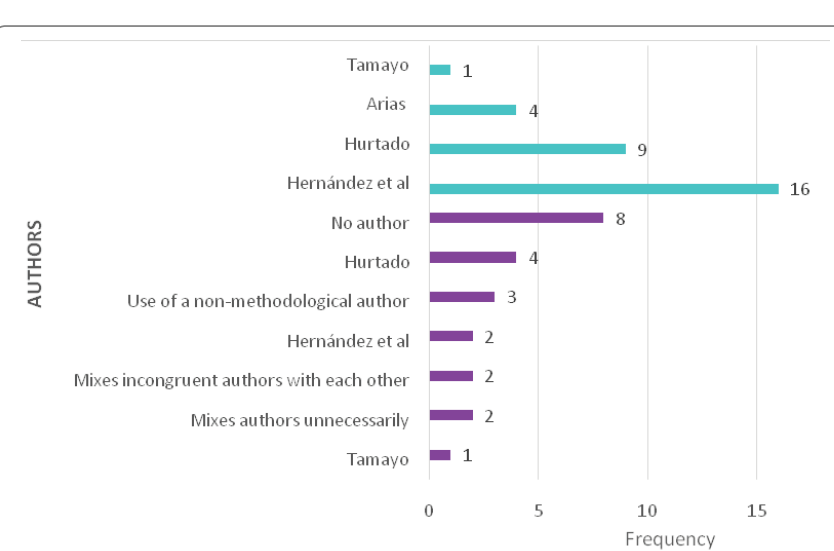

Image 9: Cited authors and errors in the citation of authors in the types of research of the Stomatology UDPs.

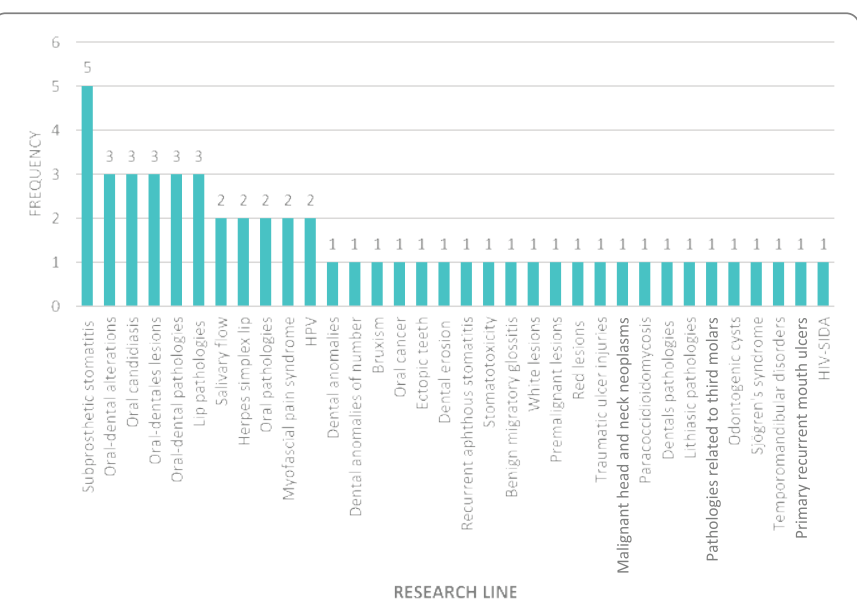

Image 10: Research Line of the Stomatology UDPs.

used, which include confusing direct observation, survey or interview with another technique (Image 11).

Among those papers that mentioned the statistical analysis technique, descriptive statistics were found in the first place with 34 of the 53 Stomatology UDPs and in second place the combination of descriptive and inferential statistics (13) (Image 12).

Out of the 13 cases that used inferential statistics, the $\mathrm{chi}^{2}$ was presented in 6 cases and on one occasion together with Fischer's exact test. In total 6 different statistical tests were used (Image 13).

Finally, as can be seen in image 14, it was found that the Software used most frequently to generate the analysis of the results was SPSS (21 times) followed by the combination of SPSS with Excel (14) and thirdly Microsoft Excel (8). On 9 occasions they did not indicate the used Software.

\section{Discussion}

This paper is part of a line of research started in the "José Tona Romero" Research Department of the Faculty of Dentistry of the University of The Andes, (Mérida, Venezuela) which began with the study by Maggiorani J, et al., whose objective was to analyze bibliometrically the UDPs from the Faculty of Dentistry of the University of The Andes between the years 2005- 2017 [6]. Therefore, the results were compared, fundamentally, with those studies and some international ones. As in those investigations, in the present 


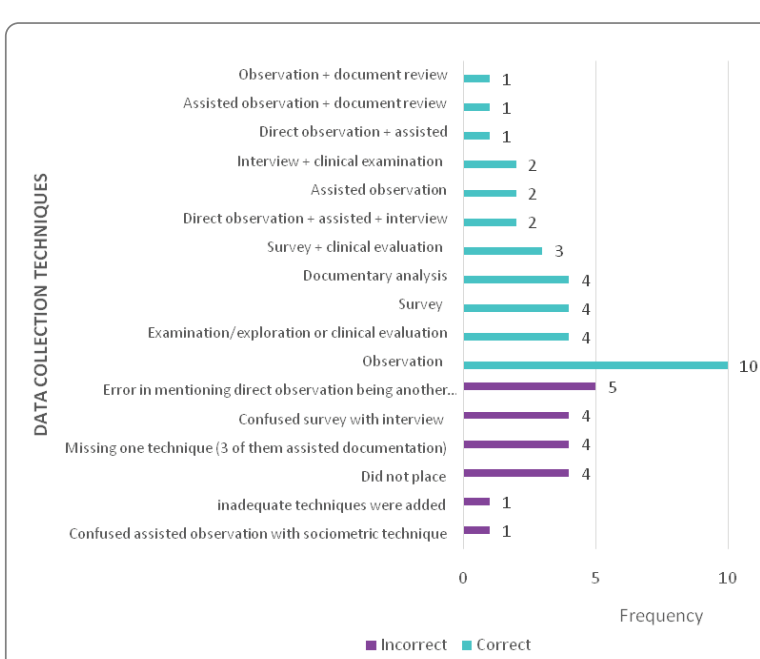

Image 11: Data collection technique of Stomatology UDPs identifying their correct or incorrect use.

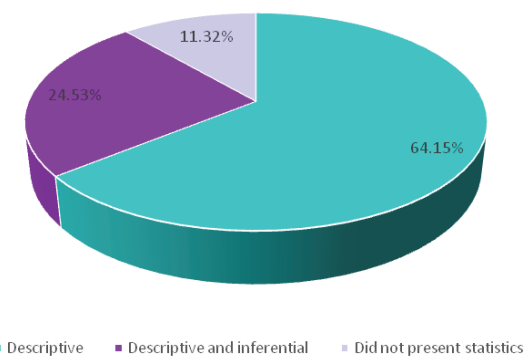

Image 12: Type of statistics used in the Stomatology UDPs.

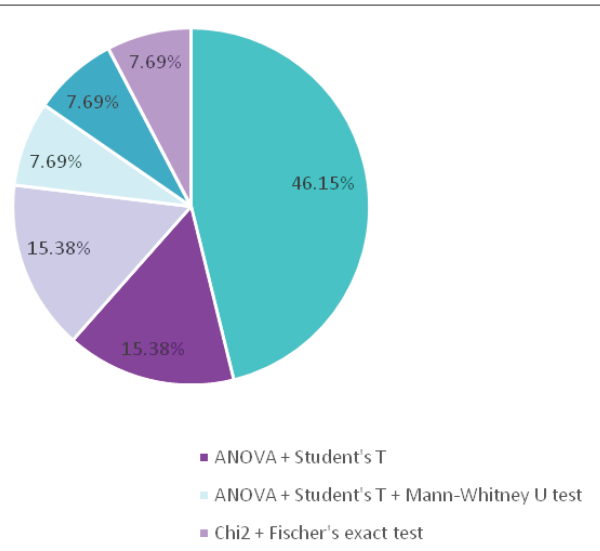

- ANOVA+ Wilcoxon

- Chi2 + Fischer's exact test

Image 13: Most used inferential statistics in Stomatology UDPs.

paper it was decided to identify the behavior of bibliometric indicators in a sufficiently wide period in time and close to the present, so that the results obtained were significant and reflect the current situation of publications scientists in the Stomatology area.

The productivity index indicated that the Stomatology UDPs represented $11.86 \%$ (53) of the 447 FOULA UDPs between the years 2009-2019. Although in the study by Maggiorani J, et al., it was mentioned that only 43 theses belonged to the Stomatology area, it is considered that this difference may be associated with the

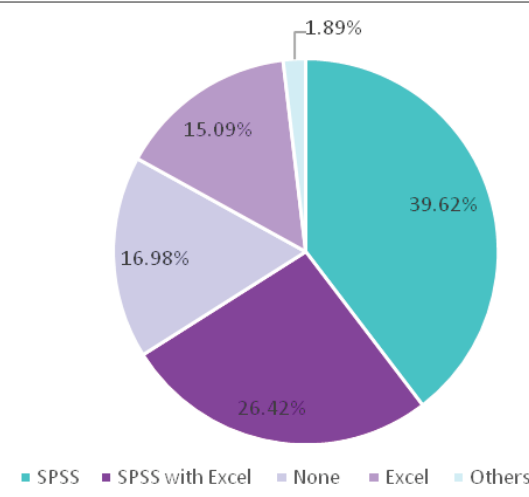

Image 14: Software most frequently used to generate the analysis of the Stomatology UDPs results.

Table 1: Author cited in the research type of the Stomatology UDPs.

\begin{tabular}{|c|c|c|}
\hline DESIGN & CLASSIFICATION & UDP \\
\hline \multirow{2}{*}{$\begin{array}{l}\text { According to the } \\
\text { Intervention }\end{array}$} & Not experimental or observational & 14 \\
\hline & Experimental & 10 \\
\hline \multirow{2}{*}{$\begin{array}{l}\text { According to the number of } \\
\text { measurements }\end{array}$} & Cross-sectional or trans-sectional & 31 \\
\hline & Longitudinal or evolutive & 7 \\
\hline \multirow{2}{*}{$\begin{array}{l}\text { According to the time in } \\
\text { which the phenomenon } \\
\text { occurs }\end{array}$} & Retrospective & 9 \\
\hline & Prospective or contemporary & 5 \\
\hline \multirow{3}{*}{ According to the source } & From File & 8 \\
\hline & Documentary & 4 \\
\hline & From Laboratory & 2 \\
\hline \multirow{2}{*}{$\begin{array}{l}\text { According to the data } \\
\text { amplitude }\end{array}$} & Multivariable & 1 \\
\hline & Univariable & 0 \\
\hline \multirow{4}{*}{ Others } & Case series & 2 \\
\hline & Case Study & 1 \\
\hline & Epidemiological & 1 \\
\hline & Prevalence & 1 \\
\hline
\end{tabular}

fact that several of these papers were assigned to other areas such as Periodontology and Pathological Anatomy, also, the present study it involves a different span of years [6]. On the other hand, the result is similar to that of Ordinola-Sierra C, et al., [20] in the University of San Martín de Porres who found in his study that $11.63 \%$ of the theses published in the period 2005-2013 belonged to the Stomatology area, however, in the research of Castro YR, et al., only $0.4 \%$ ( 1 of 269) of the UDPs were from this area [21]. Castro YR, in the study, carried out in the theses of the Faculty of Dentistry of the National University of San Marcos in Peru indicated that Stomatology represented 3.22\% (6 of 186) of the papers, having a frequency close to that found in Coronel C, et al. [22] with $4.34 \%$ (16 of 368) [3].

Regarding the legal bases, no mention was made in any of the UDPs. This differs from the reported by the research by Maggiorani J, et al., which showed a $6 \%$ legal basis. This discrepancy may be because some studies carried out in children and adolescents, such as the FOULA UDPs of Pediatric Dentistry, require compliance with some laws [6,7].

On the other hand, the ethical or bioethical aspects were evidenced in $58 \%$ of the cases, a lower figure compared to the study by OrdinolaSierra C, et al., [20] (73\%) and Coronel C, et al. [22] (73.37\%). 
Table 2: Correct or incorrect use of the cited authors in the design research on the Stomatology UDPs [23,24].

\begin{tabular}{|l|c|c|}
\hline \multicolumn{1}{|c|}{ DESIGN AUTHOR } & CORRECT & INCORRECT \\
\hline $\begin{array}{l}\text { Channels with a design that does not belong } \\
\text { to it (Channels uses it as type) }\end{array}$ & 1 \\
\hline $\begin{array}{l}\text { The design is mentioned in the type and } \\
\text { without an author }\end{array}$ & 1 \\
\hline $\begin{array}{l}\text { Mix Arias with Hurtado J, et al. (the latter } \\
\text { incomplete) }\end{array}$ & & 1 \\
\hline Mix Arias and Hulley (the latter incomplete) & & 1 \\
\hline $\begin{array}{l}\text { Mixes Hernandez R, et al., with another } \\
\text { author not mentioned }\end{array}$ & 1 \\
\hline $\begin{array}{l}\text { Mixes Hernández R, et al., and Hurtado J } \\
\text { (both incomplete) }\end{array}$ & & 1 \\
\hline $\begin{array}{l}\text { Mixes Hernandez R, et al., and Arias indicating } \\
\text { designs that are not both }\end{array}$ & & 1 \\
\hline $\begin{array}{l}\text { It uses the complete Hurtado J, et al. design } \\
\text { but some of them are placed in type }\end{array}$ & & 1 \\
\hline $\begin{array}{l}\text { Arias with a design that does not belong to } \\
\text { him }\end{array}$ & & 2 \\
\hline $\begin{array}{l}\text { Hernandez R, et al., with a design that does } \\
\text { not belong to them }\end{array}$ & & 3 \\
\hline No author mentioned & & 4 \\
\hline Uses of a non-methodological author & & 7 \\
\hline Hernández R, et al., incomplete & & \\
\hline Hurtado J, et al., incomplete & & \\
\hline Hernández R, et al., & & \\
\hline Hurtado J, et al. & & \\
\hline Ruiz and Murillo & & \\
\hline Ramón Torrell & & \\
\hline Tamayo and Tamayo & & \\
\hline Grajales (calls them type) & & \\
\hline Arias & & \\
\hline & & \\
\hline
\end{tabular}

However, between 2017-2019, their presence is observed in $100 \%$ of the papers, this might be due to the promotion of the implementation of this section by FOULA.

The total number of background registered in this paper was 699, with an average of 13 antecedents per paper, a figure very similar to the Maggiorani J, et al., the paper which presented (12) Meanwhile, the references presented an average of 52.98 per UDP in Stomatology, similar to the FOULA's totals thesis article6 (51) [6].

Regarding the critical apparatus, $75.47 \%$ of the cases used the Vancouver system, due to the FOULA Research Department recommended its use as of 2010 to adapt to what is most used in the medical discursive community, this figure increases to $83 \%$ of cases if they are only taken into account from that year on. This percentage is higher than that observed in the study by Maggiorani J, et al., between 2005 and 2017 (49\%) [6]. This difference is because that the previous papers began to be analyzed in 2005 and those of Stomatology since 2009 , which is the year in which they started to be available in digital.

In the UDPs of the FOULA, the approach is not required, that may be why only $47 \%$ of the Stomatology theses expressed it, and also, some authors used by the students do not implement them in their classification. When they were used, the quantitative (84\%) prevailed over the qualitative (16\%), Now, when comparing the results with the study by Maggiorani J, et al., greater participation of the quantitative approach (83\%) was also found, a figure very similar to the value obtained (84\%) from the present investigation [6].

Regarding types of research, along with Maggiorani J, et al., (53\%), in the present paper, the most widely used research was the descriptive one with $58.49 \%$ [6]. To conclude, Hernández R, et al., stood out as the authors most used correctly on 16 occasions, followed by Hurtado J, et al., on 9, presenting failures in their signaling in $42.31 \%$ of the cases $[23,24]$.

A large proportion of studies were detected with a cross-sectional design of $60.78 \%$ according to the number of measurements. This type of study is considered to be of special utility when analyzing very prevalent pathologies or conditions [25]. Along the same line of ideas, the most predominant design according to the intervention was the observational or non-experimental (27.45\%), according to the period in which the information was captured, $17.65 \%$ were retrospective. A characteristic that resembles the study by Maggiorani J, et al., $(43.88 \%$ and $28.93 \%$ respectively), showed that the cross-sectional and nonexperimental studies were the most prolific [6]. For his part, Coronel C, mentions that $93.75 \%$ (15 out of 16 ) of his oral medicine studies are cross-sectional and observational respectively [22], while Castro YR and Ordinola-Sierra C, et al., state that observational research represents $100 \%$ (6 of 6) and $52.5 \%$ of the designs used in Stomatology, respectively $[3,20]$.

In the same way, as in research types, the most used author in the designs was Hernández R, et al., (13.21\%) [23]. On the other hand, when the research design was expressed, there were $67.92 \%$ errors when trying to point out the methodological author or authors used. Both in the research approaches, types and designs, a significant decrease in taxonomic errors (20\%) was observed between the years 2017 and 2019, possibly due to a greater follow-up by the professors of the FOULA Research Chair and the same tutors regarding those sections.

A large part of the Stomatology UDPs included in this study presented subprosthetic stomatitis as a line of research with $9.49 \%$, followed by oral-dental lesions, oral candidiasis, oral-dental lesions and pathologies, as well as labial pathologies with a frequency of $5.66 \%$ each. Therefore, it can be deduced that the FOULA total prostheses field has had great participation in these papers.

The most applied data collection technique was observation (alone or with another technique) in $34.70 \%$; however, it is important to highlight that their figure is much lower than those reached in the total theses of FOULA6 (62.33\%). In the studies by Castro YR [21] and Coronel C, et al. [22], the observation was the most preferred technique in the Oral Medicine area with $83.33 \%$ (5 of 6) and $62.5 \%$ (10 of 16). Besides, it was possible to appreciate that $35.85 \%$ made an error when indicating the technique used. In the same way, as in the taxonomy, the errors improved a lot as they were not perceived between the years 2017 and 2019.

Finally, in the statistical analysis, the usage of descriptive statistics was evidenced with $64.15 \%$, followed by descriptive statistics with inferential $(24.53 \%)$. Case akin to the study of the total UDP of FOULA6, in which the statistics alone (without inferential) were predominant with $51.45 \%$. 


\section{Conclusions and Recommendations}

We conclude that in the period 2009-2019, dental research in the Stomatology area was characterized by the following trends:

In this bibliometric study, the 53 UDP of Stomatology at FOULA included professors from 15 different chairs. After the Chair of Stomatology, the Chair of Pathological Anatomy stood out.

During the development of the research carried out, a greater predominance, in the quantitative approach over the qualitative, of the descriptive type of research over the explanatory one. Regarding the methodological design, the transversal design prevailed over the longitudinal one and the non-experimental or observational design over the experimental one; However, a very high number of methodological inconsistencies were observed, either due to omission or due to exaggeration in the usage of authors who contradict each other, only $16.98 \%$ of the papers presented an adequate taxonomy. Despite this, between 2017 and 2019 a substantial improvement was observed.

The most employed data collection technique was an observation. However, it was found that in up to $35.85 \%$ of the cases an error was made by omission, due to misinterpretation or ignorance of it. One particular mistake that was observed was confusing direct observation with another data collection technique. An improvement was also observed from 2017 as no errors were found from that year to 2019.

Regarding the statistical analysis, the descriptive statistics stood out as expected when relating them to the most used types and research designs.

The 53 UDPs of Stomatology were represented by 34 different lines of research so that a large part of them can continue to be developed since in 28 of them only one or two studies were carried out.

This bibliometric analysis in the undergraduate theses in the Stomatology area is an unprecedented paper of the FOULA, and no papers or sources with similar characteristics have been found that serves as a reference to compare the results obtained on the authors and types of errors found in the focus, type and design of the investigation. Therefore, it would be very useful to extend the bibliometric analysis to other faculties, generating a reference for future research.

As in previous papers in this line of research, greater communication between tutors and professors of the FOULA Research Department is recommended. In the same way, a more direct relationship and communication are required between the tutors and the UDP juries since sometimes contradictory corrections are indicated to the students by having different ways of approaching the reading of the paper and, therefore, the methodology applied to them.

\section{References}

1. Gil M (2018) Tendencias de investigación científica en la Facultad de Odontología de la Universidad de Carabobo. Universidad de Carabobo, Venezuela.

2. García K, Cloquell D (2020) Bibliometric study of the special degree projects on surgery presented by the Faculty of Dentistry of the Universidad de Los Andes, 2005-2017. Rev Venez Invest Odont IADR 8: 5-25.

3. Castro YR (2018) Bibliometric indicators of the thesis supported by students of Dentistry, Peru. Edumecentro 10: 1-19.

4. Facultad de Odontología, Universidad de Los Andes, Consejo técnico de Trabajo Especial de Grado (2014) Reglamento del Trabajo Especial de Grado de la Facultad de Odontología. Mérida-Venezuela.
5. Ramírez E, Valero D, Rodríguez R, Cloquell D (2020) Bibliometric Study of Bachelor Theses in Operative Dentistry Defended at the Universidad De Los Andes School of Dentistry, 2005-2017. IDEULA.

6. Maggiorani J, Cloquell D, Izarra E, Bastardo K (2019) Bibliometric Study of the Final Course Paper in the Faculty of Dentistry of the Universidad De Los Andes 2005-2017. Rev Venez Invest Odont IADR 7: 21-40.

7. Parra G, Cloquell D (2020) Bibliometric study of bachelor theses in pediatric dentistry defended at the Universidad de Los Andes School of Dentistry, 2005-2017. Rev Venez Invest Odont IADR 8: 58-74.

8. Escorcia T (2008) El análisis bibliométrico como herramienta para el seguimiento de publicaciones científicas, tesis y trabajos de grado. Pontificia Universidad Javeriana, Facultad De Ciencas, Carrera de Microbiologia Industrial, Bogotá, Colombia.

9. Esther GM, Vanessa PG, Filomena ES, Carlos BA (2019) Análisis bibliométrico de las revistas de Odontopediatría incluidas en JCR durante el periodo comprendido entre 2008-2018. Facultad de Medicina y Odontología, Universitat de València, España.

10. Ramírez-Rodríguez J, Becerra-Figueroa L, Ramírez-Ortiz G, Moreno F, Moreno S (2018) Bibliometric characterization of colombian dental journals indexed in the second update of 2014 Publindex. Rev Estomatol 26: 10-20.

11. Restrepo-Valencia L, Cano A, Castañeda C, Sánchez RD, GonzálezAriza S (2015) Scientific production analysis of the journal "CES Odontología" in the last 10 years. Revista CES Odontología 28: 119131

12. Patrón C, del Carmen LJM, Sylvia P, Bettina D (2014) Bibliometric analysis of the scientific production in Odontoestomatología journal. Odontoestomatología 16: 34-43.

13. Dhillon JK, Gill NC (2014) Contribution of Indian pediatric dentists to scientific literature during 2002-2012: a bibliometric analysis. Acta Inform Med 22: 199- 202.

14. Fereira JAL, Rosas CYR, Alvarez MA, Fonseca CIG (2017) The Highest Impact Dentistry Journals: A Review of their Performance in the Journal Citation Reports. Int J Odontostomat 11: 287-293.

15. Corrales IE, Reyes JJ, Fornaris Y (2016) Bibliometric analysis of the Journal of Oral Research. Period 2012-2015. J Oral Res 5: 188-193.

16. Castro-Rodríguez Y (2015) Perfil bibliométrico de la producción científica de una revista odontológica peruana: 2005-2014. KIRU 12: 80-84.

17. Uribe SE, Uribe DS, Schumanc WA (2014) Bibliometric profile of Chilean dental journals during the 2002-2012 period. Rev Clin Periodoncia Implantol Rehabil Oral 7: 76-84.

18. Yparraguirre-Carbajal J, Alfaro-Carballido D, Telles-Mimbela P, BorjaGuerrero P (2013) Estudio bibliométrico de los artículos publicados en la revista odontológica de una universidad peruana. KIRU 10: 3237.

19. Poletto VC, Faraco Junior IM (2010) Bibliometric study of articles published in a Brazilian journal of pediatric dentistry. Braz Oral Res 24: 83-88.

20. Ordinola-Sierra C, Tello-Chávez V, Vargas-Pérez J, Rivera-Vílchez R, Alfaro-Carballido D (2014) Analysis of Undergraduate Thesis of the School of Dentistry of a Peruvian University, 2005-2013. KIRU 11: 25-31.

21. Castro YR, Cósar-Quiroz J, Arredondo-Sierralta T, Sihuay-Torres K (2018) Producción científica de tesis sustentadas y publicadas por estudiantes de Odontología. Educ Med 19: 85-89. 
22. Coronel C, Tffany K (2016) Análisis estructural de las tesis de pregrado de estudiantes de estomatología de la Universidad Privada Antenor Orrego Trujillo, 2010-2016. Universidad Privada Antenor Orrego. Perú.

23. Hernández R, Fernández C, Baptista P (2014) Metodología de la Investigación. $6^{\text {th }}$ Edition, Mc Graw Hill Education, México.

24. Hurtado de Barrera J (2006) El proyecto de investigacion: metodología de la investigación holística. $4^{\text {th }}$ Edition, Bogotá; Colombia: Quiron ediciones.

25. Couto LV, Del Pozo PP (2017) De qué evidencia disponemos en traumatología dentaria? Estudio bibliometrico. Odontología pediátrica 25: 200-208. 